\title{
Mobilidades contemporâneas, espaços gendrados: os múltiplos espaços discursivos da literatura de autoria feminina
}

\section{Sandra Regina Goulart Almeida}

Professora Associada da Universidade Federal de Minas Gerais, bolsista de produtividade em pesquisa $\mathrm{CNPq}$, bolsista pesquisador mineiro FAPEMIG.

Resumo: Este artigo discute as representaçōes de gênero nas literaturas contemporâneas de autoria feminina no contexto do presente cenário da globalizaçẩo e dos constantes movimentos de trânsito entre culturas diversas.

Palavras-chave:crítica literária feminista; literatura inglesa; diáspora
Abstract: This article discusses gender representation in contemporary literature by women writers in view of the present globalized scenario and the constant movement of transit among cultures.

Keywords: feminist literary criticism; English literature; diaspora 

I don't feel the need for allegiances. To me, home is nowhere in particular.

Monica Ali

\section{Mobilidades contemporâneas}

O advento da globalização, hoje reconhecida como um dos mais significantes fenômenos da contemporaneidade, vem contribuindo significantemente para produzir uma cultura em constante movimento e, por conseguinte, para o surgimento de um cenário de grandes mudanças sociais, econômicas e culturais em todo o mundo. Como um fenômeno complexo e multi-axial, a globalização informa não apenas o fluxo transnacional de capital, mas também o de pessoas em espaços sociais e zonas de contato nas quais diferentes perspectivas culturais se encontram e, inevitavelmente, colidem entre si. Nesse caso, interessa-nos analisar em quais circunstâncias e condições esses movimentos e contatos contínuos ocorrem e quais as consequências para as representações e construções de gênero nas produções artísticas, culturais e literárias contemporâneas.

Nesse contexto, podemos salientar o papel crucial de artistas, escritoras e teóricas ao projetarem, através da escrita, uma experiência do devir em trânsito, como uma possível forma de resistir a iniciativas globalizantes, deslocar posicionamentos, abrir novas frentes e criar modelos alternativos que fomentem um diálogo que, em um contexto transnacional, possa levar a formas instigantes de percepção e questionamentos dos discursos da contemporaneidade (BRYDON, 2001, p. 68). Para Brydon, a globalização acaba por questionar um posicionamento por vezes simplista da conexão que necessariamente é estabelecida, como formula Bhabha, entre a escrita e a nacionalidade (BRYDON, 2001, p. 62).

$\mathrm{O}$ interesse central pelas metáforas espaciais que permeia especificamente a literatura contemporânea em um contexto transnacional nos permite indagar, entre 
outras questões, como textos literários são veículos significativos para discutir os espaços de enunciação da atualidade e mesmo a negação desse espaço por meio da teorização de um não-lugar (AUGÉ, 1994, p. 2-5), do deslocamento, da desterritorialização, dos desraizamentos e, principalmente, dos possíveis entre-lugares que o sujeito da contemporaneidade habita. Permite-nos, principalmente, ponderar como a experiência da mobilidade, do devir em trânsito, pode ser pensada como uma experiência intelectual, de uma ética que é permanentemente questionada pelo processo de estar em contato constante com o outro.

A experiência dos sujeitos em trânsito é frequentemente descrita em termos de pluralidade, fragmentação, multiplicidade e, sobretudo, da condição de entre-lugar do dito sujeito diaspórico, seja essa uma experiência de alienação (um sentimento de não pertencimento) ou mesmo de liberação (no sentido que dicotomias são frequentemente anuladas pela vivência em trânsito). Alguns críticos apontam como uma consequência relevante do processo de desterritorialização o fato de que a lógica bi-polar que tem dominado o pensamento ocidental e a geopolítica contemporânea não mais pode ser sustentada diante dos movimentos de deslocamento humano presenciado nos dias atuais. Na verdade, a diáspora contemporânea, como a percebemos hoje, reescreve a nação e o projeto nacional pelo fato de os sujeitos migrantes substituírem um espaço nacional por um outro, por vezes, mais desejável, mas carregando consigo uma bagagem indelével daquilo que deixaram para trás (GEORGE, 1996, p. 200), contribuindo assim para modificar a compreensão e mesmo um suposto conceito de nação da terra adotada.

Nesse contexto, identidade e espaço se tornam conceitos imbricados na ambivalente experiência dos sujeitos em trânsito nas sociedades cosmopolitas. James Clifford argumenta que, em uma perspectiva cosmopolita, identidade nunca se refere apenas a um espaço ao qual se 

necessariamente pelos problemas que o multiculturalismo e a globalização acabam de nos colocar e que, de certa forma nos fazem renegociar as certezas \& prioridades das agendas teóricas feministas" (2005, p. 13).

$\mathrm{O}$ advento do multiculturalismo e a presença cada vez mais marcante dos efeitos da globalização na obra de escritoras contemporâneas faz com que não apenas indaguemos, como sugere acertadamente Heloisa Buarque de Hollanda, "que lugar têm as culturas e demandas feministas locais frente à mágica da globalização?” (2005, p. 13), mas que também analisemos como esses fenômenos da contemporaneidade são vislumbrados por essas escritoras e como surgem problematizados de formas variadas em suas obras. Pode-se perceber como várias autoras contemporâneas, antes voltadas para narrativas que tratavam prioritariamente de discutir a situação da mulher com relação às questões de gênero no campo privado, têm abordado questões mais abrangentes, mas não menos problemáticas, com relação à presença feminina nesse novo contexto sócio-cultural.

A presente análise parte do pressuposto de que, como afirma Spivak, "se o sujeito colonial era principalmente um sujeito de classe e se o sujeito do póscolonialismo é um sujeito racializado, então o sujeito da globalização é gendrado" (2000, p. 123). A argumentação de Spivak chama a atenção para a ênfase nas relações de gênero suscitadas pela globalização. Se antes o foco estaria nas questões de classe e raça, na contemporaneidade a mulher se torna o alvo de sociedades civis internacionais e, consequentemente, é incorporada como uma parte integral do projeto global para o estabelecimento de uma nova ordem social e econômica (SPIVAK, 2000, p. 123). Para vários críticos, a novidade da globalização deve ser necessária e inevitavelmente articulada com as questões de gênero por meio da feminização, hoje observada, dos meios de produção econômica e cultural (MARX, 2006, p.1-4).

Pode-se verificar, por meio da obra de escritoras contemporâneas, como as configurações da 
contemporaneidade têm destacado um locus de enunciação nitidamente feminino. Fica evidente, através dessas análises, como o papel das mulheres nesse novo contexto sociocultural torna-se um elemento diferenciador e como o questionamento dos papéis de gênero nesse espaço global, híbrido e multicultural tem perpassado a literatura de autoria feminina contemporânea. Com frequência, essas escritoras delineiam narrativas que expõem as contradições e ambiguidades do mundo global e que questionam noções preestabelecidas de identidades subjetivas e nacionais. Ao problematizar, por meio de uma narrativa desestabilizadora, as políticas identitárias que permeiam as visões do mundo contemporâneo, privilegiam uma escritura que se insere nas narrativas da globalização e do cosmopolitismo e que é inevitavelmente perpassada pelas perspectivas de gênero, contribuindo assim para interrogar de forma incisiva as práticas discursivas da contemporaneidade.

Nesse contexto, cabe ressaltar a forma como a crítica literária feminista recente tem interagido face aos movimentos críticos e culturais da contemporaneidade e como funciona como "um espaço de políticas contestatórias” (ROBBINS, 1998, p.12). Pode-se observar, inclusive, um número cada vez mais crescente de obras de autoria feminina que enfocam os devires de personagens femininas que habitam territórios liminares, espaços de movência, deslocamento e desraizamento. Como nos lembra a escritora nascida em Bangladesh $€$ radicada na Inglaterra, Monica Ali, na citação que abre este texto, "Não sinto necessidade de filiações, Para mim, o lar não é nenhum lugar em especial" (CRAIG, 2003, p. 3). Nesse sentido, para Ali e várias outras escritoras contemporâneas, não basta simplesmente refletir em suas obras sobre o espaço no qual habitam. É importante que suas narrativas privilegiem filiações múltiplas, móveis e deslizantes. São vários os possíveis lares a serem habitados. Pode-se verificar, através da obra dessas escritoras, como a configuração da nova diáspora da 
contemporaneidade tem destacado um lócus de enunciação nitidamente feminino. Fica evidente, através dessas análises, como o papel das mulheres nesse novo contexto sociocultural torna-se um elemento diferenciador dessa nova diáspora, como aponta Spivak (1996, p. 249252) e como o questionamento dos papéis de gênero nesse espaço híbrido e multicultural tem perpassado a literatura de autoria feminina contemporânea.

\section{Os múltiplos espaços discursivos de Monica Ali}

Se, por um lado, esse mundo contemporâneo se caracteriza pela confluência de locais geopolíticos, pela eliminação de fronteiras e compartilhamento de espaços sociais; por outro, mostra-se cada vez mais sectário e excludente nas práticas cotidianas, principalmente na esfera das relações de gênero. Essa ambiguidade está no cerne do romance Brick Lane (2003), da escritora Monica Ali. De origem muçulmana, nascida em Bangladesh, filha de pai bangladeshiano e mãe inglesa e radicada na Inglaterra, Ali expõe, por meio de uma narrativa poética e inquietante, as inerentes contradições do mundo globalizado da contemporaneidade, sob uma perspectiva marcadamente de gênero.

Brick Lane, o primeiro romance de Ali, aborda a vivência marcante de duas personagens femininas que se encontram ambas inescapavelmente às margens da sociedade à qual pertencem. A personagem central, Nazneen, na verdade, faz parte da nova diáspora descrita por Spivak (1996, p. 249-252), desempenhando um papel relevante nessa nova configuração geopolítica. Tanto na concepção de Spivak (1996), como também na de James Clifford (1994), Avtar Brah (1996), Rey Chow (1993) e Smaro Kamboureli (2000), as mulheres ocupam um papel crucial na nova diáspora, pois esse grupo gendrado se encontra atualmente em grande demanda pelos organismos internacionais. Além disso, os movimentos migratórios da 
atualidade acabam por expor e, por vezes, modificar os mecanismos ideológicos, sociais e culturais que operam nas relações de gênero. Nas novas configurações políticas e sociais em que o elemento feminino se faz fortemente presente, um questionamento do papel desse sujeito, que é duplamente obliterado por questões não somente de gênero, mas também de raça e classe, leva ao surgimento de uma escritura, como no caso de Ali, que se desloca como seus sujeitos em busca de novos parâmetros e novas dimensões críticas e poéticas. A narrativa de Ali faz parte dessa nova configuração, ao apresentar as inerentes contradições do mundo globalizado da atualidade e abordar as trocas e transferências entre culturas diversas, demonstrando, por vezes, como esse contexto corrobora na construção de identidades múltiplas e híbridas perpassadas inevitavelmente por múltiplas afiliações e pelas conflitantes noções de gênero, etnia, raça e classe.

O romance de Ali tem em comum com várias outras narrativas contemporâneas o enfoque em uma estória centralizada em uma figura feminina que vive em um entrelugar e é, portanto, obrigada a renegociar sua identidade, apresentando diversas versões de identidades e subjetividades em trânsito, em constante deslocamento, sempre por devir, por se tornar algo. É uma narrativa que explora a ambiguidade, o desraizamento, o conflito pelo fato de essa personagem habitar um entre-lugar deslizante e que apresenta as inerentes contradições do mundo globalizado da atualidade, enfatizando as inevitáveis trocas e transferências entre culturas diversas.

Brick Laneexplora ainda um conceito mais amplo de mobilidade que pode ser compreendido como uma forma de cosmopolitismo, ou, como argumenta Bruce Robbins, como uma cosmopolítica. Segundo Robbins, "como a diáspora, o cosmopolitismo oferece algo mais do que uma galeria de identidades virtuosas, elegíveis. Aponta, em vez disso, para um domínio de políticas contestatórias [...] [a cosmopolítica] como uma área ao mesmo tempo dentro e além da nação [...] habitada por uma variedade de cosmopolitismos"(1998, p. 12). É nesse contexto 
relativo a movimentos globais e tanto ao cosmopolitismo quanto à cosmpolítica que podemos analisar também a obra de Mônica Ali, ou seja, questionando de que forma esses novos conceitos da contemporaneidade são apresentados e descritos no texto em tela e como ele corrobora para fomentar um "domínio de políticas contestatórias”, como sugere Robbins.

O romance de Monica Ali nos abre uma nova perspectiva com relação às narrativas da diáspora, por abordar um cenário de conflitos decorrentes da nova ordem global instaurada com os atentados de 11 de setembro e seus prolongamentos. Acerca-se ainda de um panorama espacial que, centrado em Brick Lane, o bairro londrino no qual habita a comunidade diaspórica de Bangladesh e no qual se ambienta a narrativa, envolve o conceito de um mundo cosmopolita, porém, sectário.

Ella Shohat observa que, com o evento traumático do 11 de setembro, a crítica feminista multiculturalista/ transnacionalista produzida na década passada adquiriu maior relevância e "urgência renovada" (2004, p. 19). Shohat salienta a importância da relacionalidade para os estudos feministas. Para ela, um entendimento relacional do feminismo é imprescindível, visto que, "inter-relacionar mapas críticos de conhecimento é fundamental em uma era transnacional, tipificada pela viagem global de imagens, sons, produtos e populações" (2004, p.20). Shohat acrescenta que "um projeto feminista relacional e multicultural deve refletir esse momento, parcialmente, novo que exige um repensar sobre designações de identidade, grades intelectuais e fronteiras interdisciplinares" (2004, p. 20). Nesse sentido, Shohat privilegia a análise relacional e multi-perspectivista do feminismo além-fronteiras em detrimento de estudos que favorecem uma "categorização clara e nítida de espaços alocados em cada região específica” (2004, p. 20). Porém, como afirma Heloisa Buarque de Hollanda, pensar a diferença hoje é "enfrentar um tempo no qual emergem, sem aviso prévio, novos e ferozes racismos, xenofobias 
radicais, intolerâncias violentas” (2005, p. 13). Nesse contexto, Hollanda pergunta, "como lidar com o próprio desgaste de uma política da diferença?” (2005, p. 18). Segundo Shohat, não se trata de pensar a diferença, sob uma perspectiva de gênero, por meio de noções essencialistas sobre diferenças culturais, mas sim de proporcionar "encontros dialógicos das diferenças", nos quais posicionamentos diferentes podem ser contrastados. Essa parece ser a noção teórica que pode ser instaurada com uma leitura gendrada do texto de Ali. Por meio de "encontros dialógicos das diferenças", Ali explora as diferentes possibilidades de articulação de gênero na contemporaneidade, quer seja por um viés emancipatório ou por uma ênfase em seu caráter opressor, como observamos em Brick Lane..

Como havia ocorrido com Arundhati Roy e Zadie Smith, o romance de Ali ganhou notoriedade e, consequentemente, uma certa impopularidade, mesmo antes de ser publicado. Como várias narrativas da diáspora, o romance de Ali teve de enfrentar a voracidade do mercado editorial, que tem privilegiado as narrativas pós-coloniais e diapóricas que possam oferecer uma aura de autenticidade aos relatos ficcionais. Ironicamente, a razão pelo imediato sucesso da obra é a mesma que direciona sua repulsa. Se, por um lado, o romance foi prontamente assimilado pelo mercado editorial global e pelos leitores por sua suposta autenticidade; por outro, foi rejeitado pela comunidade bangladeshiana justamente por, em sua visão, não fornecer um relato "real", mas sim preconceituoso e estereotipado da comunidade. O conflito se materializou com defensores dos dois lados: a favor da liberdade de expressão e da autonomia do escritor, o indiano Salman Rushdie, e contra, surpreendentemente, a feminista inglesa Germaine Greer, que critica o efeito nocivo do romance para comunidades minoritárias nos grandes centros urbanos.

Se Ali nos oferece uma nova visão da diáspora contemporânea é precisamente nessa seara: ao questionar noções de autenticidade cultural e se negar a fornecer uma 
visão unívoca de um fenômeno sócio-cultural que também é seu. Balizando seu questionamento em noções de gênero que, de uma certa forma, escaparam à maioria dos críticas, Ali aborda questões centrais para a compreensão das relações de gênero, em um contexto global de culturas em trânsito e sociedades cosmopolitas.

Brick Lane tem como enfoque central duas personagens femininas - Nazneen e Hasina - que apresentam trajetórias completamente opostas com consequências igualmente diversas. Como enfoque central, deparamo-nos com o conceito enraizado de destino ("Fate"), que é projetado sobre as personagens centrais pela figura materna. Nazneen acolhe os desígnios do destino e, entre outras aceitações, casa-se, aos dezoito anos, com o marido escolhido pelo pai, vinte anos mais velho do que ela e que a leva a deixar a terra natal e imigrar para a Inglaterra. Hasina, por outro lado, vive em constante afrontamento com esses mesmos valores e casa-se por amor, desafiando as convenções do casamento arranjado e de comportamento feminino padronizado pela sociedade local. Ao longo da narrativa, porém, esse padrão dicotômico que informa as escolhas individuais é, aos poucos, quebrado por meio de uma inversão que ocorre em suas vidas que, se ainda preserva as escolhas individuais, aponta para outros fatores decisivos nas relações de gênero das sociedades contemporâneas.

A transformação que se processa em Nazneen, como consequência do deslocamento que lhe é imposto, assume papel central na narrativa, cuja final nos é apresentado já nas primeiras páginas:

What could not be changed must be borne. And since nothing could be changed, everything had to be borne. This principle ruled her life. It was mantra, fettle, and challenge. So that, at the age of thirtyfour, after she had been given three children and had one taken away, when she had a futile husband and been fated a young and demanding love, when 
for the first time she could not wait for the future to be revealed but had to make it for herself, she was as startled by her own agency as an infant who waves a clenched fist and strikes itself upon the eye. (ALI, 2003, p. 5)

Ao final de sua estória, encontramos justamente este movimento de agenciamento mencionado no início do romance: Nazneen reconhece sua capacidade de ação, ao tomar as rédeas de seu próprio destino e optar por ficar em Londres, sozinha com as duas filhas, em vez de retornar a Bangladesh com o marido fracassado. Nazneen rejeita ainda o amante muçulmano, nascido na Inglaterra, mas filho de pais bangladeshianos, que via nela uma expressão da autenticidade à qual jamais havia tido acesso. Nazneen reflete sobre a situação: "How did Karim see her? The real thing, he'd said. She was his real thing. A Bengali wife. A Bengali mother. An idea of home. An idea of himself that he found in her" (ALI, 2003, p. 382). Vemos aqui a tradicional equivalência entre a mulher e a terra almejada. Karim, que jamais pôde visitar Bangladesh, mas que assume para si o posicionamento revolucionário e o fundamentalismo islâmico que caracteriza a comunidade à qual pertence, anseia por se tornar oficialmente o esposo de Nazneen, pelo que ela simboliza, em sua percepção: metonimicamente, para ele, ela representaria a terra idealizada à qual jamais teve acesso. Para Nazneen, não é o suposto "pecado" que haviam cometido que a impede de aceitar a proposta de casamento de Karim, mas sim a compreensão de ter finalmente obtido um certo poder e agenciamento diante de sua própria trajetória de vida. Nazneen argumenta: "Oh Karim, that [the sin] we have already done. But always there was a problem between us. How can I explain? I wasn't me, and you weren't you. From the very beginning to the very end, we didn't see things. What we did - we made each other up" (ALI, 2003, p. 382). Nesse momento, Nazneen reconhece que ambos fabricaram imagens que correspondem a seus 
anseios, mas que são alheias ao momento histórico em que vivem. Percebe o papel que exerce para Karim e como esse relacionamento adquiriu, para ela, uma importância simbólica em seu processo de auto-reconhecimento, independência e agenciamento.

Por outro lado, Chanu, o marido de Nazneen, que, como vários personagens masculinos em romances de autoria feminina que abordam a questão diaspórica sob uma perspectiva feminista (Michelle Cliff, Bushi Emecheta,), sofre da "Going Home Syndrome" e, portanto, opta pelo retorno como tantos exilados. Nazneen, entretanto, escolhe permanecer na Inglaterra com as duas filhas claramente caracterizadas como sujeitos híbridos com múltiplas afiliações.

O final, que tanta polêmica causou, somente pode ser entendido se vislumbrado em termos de concepções de gênero que perpassam todo o texto de Ali. Enquanto Hasina, a irmã que vive em Bangladesh, mas que não consegue se realizar ou se libertar, mesmo mantendo uma constante postura transgressora dos papéis de gênero, sem, contudo, conseguir transpor os limites de tais representações, Nazneen consegue finalmente vencer os obstáculos impostos pela tradição à qual sempre aderiu. $\mathrm{Na}$ cena final, que funciona para Nazneen, simbolicamente, como o momento da conscientização de sua emancipação, as filhas levam Nazneen para realizar um sonho antigo: esquiar em um ringue de patinação. Nazneen, porém, observa, "But you can't skate in a sari" - como se dissesse que não se pode conciliar tradição e modernidade. E sua amiga Razia responde, "This is England. ... You can do whatever you like" (415). Esse final, que, à luz da percepção da diáspora contemporânea, parece ingenuamente laudatório e um tanto piegas, somente pode ser compreendido se levarmos em consideração as questões abordadas, ao longo do texto, com relação à presença da mulher no cenário de movimentos globais.

Como nos lembra Spivak, Clifford, Kamboureli e Chow, as mulheres como sujeitos diásporicos ocupam um 
lugar inquietante e altamente problemático, mas não expresso de forma simétrica e homogênea, mas sim diversificada e heterogênea. Essa nova diáspora da contemporaneidade apresenta como elemento diferenciador o papel das mulheres, que as insere na lógica do mercado global conferindo, assim, novas significações aos contatos culturais híbridos. Não há dúvida de que essas novas significações abrem novas perspectivas de interações não somente entre um mesmo grupo sociocultural, mas também entre culturas díspares.

A experiência de estar em um mundo cosmopolita, mesmo que alijada do poderio econômico ocidental e limitada ao universo de Brick Lane, é para Nazneen uma prática libertadora. É Nazneen que consegue garantir o sustento da família, por meio do trabalho de costura, quando o marido desempregado não consegue alternativa de trabalho. É ainda ela que garante o pagamento das dívidas do marido e que desafia a agiota, conterrânea de Bangladesh que explora a família, e que assegura para as filhas a possibilidade de permanecerem na Inglaterra. Ela é, portanto, o instrumento que viabiliza as modificações nas estruturas de gênero para si e sua família. Apesar de seu papel tradicional na estrutura socioeconômica das sociedades globais, como objeto de demanda do mercado global, como lembra Spivak, Nazneen é, mesmo assim ou talvez por isso mesmo, capaz de atuar como elemento agenciador das mudanças de papel de gênero no contexto em que vive.

Brick Lane, no entanto, em vez de exaltar a dinâmica contemporânea do devir em trânsito, como pode parecer à primeira vista, apresenta a ambiguidade latente dos fenômenos atuais, inclusive diante de uma perspectiva de gênero. Chama a atenção o posicionamento das mulheres que, juntamente com Karim, assumem uma atitude em defesa do islaminismo diante da reação ocidental aos atentados de 11 de setembro. A insistência em usar a burka assume para elas um papel desafiador das convenções ocidentais, que faz lembrar da colocação 
de Spivak quanto ao aumento da ocorrência do ritual suttee na Índia após a intervenção inglesa e sua força política: o corpo feminino assume metaforicamente o fardo e a responsabilidade pelo momento histórico como espaço contestatório de repúdio às intervenções ocidentais nas tradições de países periféricos (SPIVAK, 1988, p. 301). Da mesma forma, em Brick Lane, "The girls who attended the last meeting, who wore hijab, had upgraded to burkhas" (229). Se, por um lado, o uso da burka é um dos mais contundentes exemplos da opressão feminina, para essas mulheres, é uma forma de resignificar o simbolismo diante de outras possíveis variáveis, mas nem por isso menos problemáticas, como a adesão aos padrões ocidentais de comportamento.

Dessa forma, Ali nos apresenta em Brick Lane uma narrativa que expõe as contradições e ambiguidades do mundo global e que questiona noções preestabelecidas de identidades subjetivas e nacionais. Nesse sentido, ao problematizar, por meio de uma narrativa desestabilizadora, as políticas identitárias que permeiam as visões do mundo contemporâneo, Ali, assim como outras escritoras contemporâneas, privilegia uma escritura da diáspora que é inevitavelmente perpassada pela perspectivas de gênero, contribuindo assim para interrogar de forma incisiva várias práticas discursivas da contemporaneidade. Essa e outras narrativas da diáspora de autoria feminina revelam a possibilidade de se refletir sobre e problematizar, por meio da literatura, o papel das mulheres no atual cenário social e geopolítico e a consequente feminização da globalização e da diáspora contemporânea. 


\section{Referências}

ALI, Monica. Brick Lane. London: Scribner, 2003.

AUGÉ, Marc. Não-lugares introdução a uma antropologia da supermodernidade. Trad. Lúcia Mucznik. Campinas: Papirus, 1994.

BHABHA, Homi K. The Location of Culture. London and New York: Routledge, 1994.

BRAH, Avtar. Cartographies of Diaspora: Contesting Identities. London and New York: Routledge, 1996.

BRYDON, Diana. Global Designs, Postcolonial Critiques: Rethinking Canada in Dialogue with Diaspora. Ilha do Desterro n. 40,2001 , p. $61-84$.

CHOW, Rey. Writing Diaspora: Tactics of Intervention in Contemporary Cultural Studies. Bloomington and Indianapolis: Indiana University Press, 1993.

CLIFFORD, James. Diaspora. Cultural Anthropologyn. 9, v. 3, 1994, p. 302-338.

CLIFFORD, James. Mixed feelings. In: CHEAH, Pheng, ROBBINS, Bruce. (Eds.). Cosmopolitics. Thinking and Feeling beyond the Nation. Minneapolits: University of Minnesota Press, 1998. p. 362-370.

CRAIG, Amanda. Monica Ali. The Sunday Times dez. 2003.

Disponível em: <http:/www.amandacraig.com/pages/ journalism/interviews/monica_ali.htm.

GEORGE, Rosemary. The Politics of Home: Postcolonial Relocations and Twentieth-Century Fiction. Berkely: University of California Press, 1996.

HOLLANDA, Heloisa Buarque. Os estudos de gênero e a mágica da globalização. In: MOREIRA, Nadilza Martins de Barros; SCHNEIDER, Liane (Orgs). Mulheres no mundo: etnia, marginalidade e diáspora. João Pessoa: UFPB, 2005. p. 13-20. 
KAMBOURELI, Smaro. Scandalous Bodies: Diasporic Literature in English Canada. Don Mills, Ondario: Oxford University Press, 2000.

MARX, John. The Femininization of Globalization. Cultural Critiquen. 63, p. 1-32, Spring, 2006.

ROBBINS, Bruce. Introduction Part I: Actually Existing Cosmopolitanism. In: CHEAH, Pheng; ROBBINS, Bruce (Eds.). Cosmopolitics: Thinking and Feeling beyond the Nation. Minneapolis: Minnesota UP, 1998. p. 1-19.

SHOHAT, Ella. Estudos de área, estudos de gênero e as cartografias do conhecimento. Trad. Viviane Heberle. In: COSTA, Cláudia de Lima; SCHMIDT, Simone Pereira. Poéticas e politicas feministas. Florianópolis: Editora Mulheres, 2004. p. 19-29.

SPIVAK, Gayatri. Can the Subaltern Speak? In: NELSON, Cary; GROSSBERG, Lawrence (Eds.). Marxism and the Interpretation of Culture. London: Macmillan, 1988. p. 271-313.

SPIVAK, Gayatri. Diaspora Old and New: Women in Transnational World. Textual Practice n.10, v.2, 1996: p. 24569.

SPIVAK, Gayatri. Foreword: Upon Reading the Companion to Postcolonial Studies. In: SCHWARZ, Henry; RAY, Sangeeta. $A$ Companion to Postcolonial Studies. Oxford: Blackwell, 2000. p. $\mathrm{xv}$-xxii. 